\title{
Reporting clinical trials: full access to all the data
}

\section{R N Rosenberg, M Aminoff, F Boller, P S Soerensen, R C Griggs, V Hachinski, M Hallett, R T Johnson, C Kennard, A E Lang, A J Lees, R Lisak, J Newsom-Davis, T A Pedley, M E Selzer, D Zochodne}

\section{Authors' right to access to all data obtained in their study}

B omedical research is becoming more complex as a result of involvement by individual investors, universities, commercial research units, and industry. Financial conflicts of interest have been the subject of many editorials and most peer reviewed journals now require any conflicts to be identified and explained when authors submit manuscripts for publication. Clear statements of industry sponsored research and author participation in corporate activities are required for evaluation of a manuscript. Full disclosure of financial interests by authors is essential to retain public trust in biomedical research, the peer review process, and the integrity of the authors and of the universities. ${ }^{1}$ We already require that each author sign a statement of his or her financial arrangements with public, private, and industry sources of support. These declarations alert the editor, reviewer, and physician reader to any potential bias in the interpretation and presentation of the data. Patients' lives may depend on an accurate and complete understanding of how and why authors obtained facts relating to therapies. Non-financial conflicts of interest between authors and corporate sponsors are of equal concern and require our attention. These include the need for an open and candid relationship between authors and the policies of the sponsoring companies with regard to academic freedom. Issues of control and complete access to all data, conduct of statistical studies and analyses, manuscript preparation, and decisions to publish are of increasing importance and concern. Corporate sponsors must not be allowed to influence publication, or indeed to prevent it, especially when the data are not supportive of their product. Authors, editors, and industry sponsors are aware of these matters and it is now time to address them. ${ }^{1}$ These issues have been addressed in recent editorials in JAMA and the New England Journal of Medicine. The editors of JAMA, The New England Journal of Medicine, Canadian Medical Association Journal, Journal of the Danish Medical Association, The Lancet, MEDLINE/Index Medicus, New Zealand Medical Journal, Journal of the Norwegian Medical Association, Dutch Journal of Medicine, Annals of Internal Medicine, Medical Journal of Australia, and the Western Journal of Medicine have all agreed to require authors to disclose details of their own and the sponsor's role in the study. ${ }^{2}$

Authors will be required to sign a statement indicating that they accept full responsibility for the conduct of the study, had access to all the data, and had the authority to publish it. An amendment was made allowing the sponsor up to 60 days to review a manuscript before publication to allow for the filing of additional patent protection, if necessary. These policies will also be incorporated into the next revision of "Uniform Requirements for Manuscripts Submitted to Biomedical Journals".

We believe that neurology journals should invoke the same philosophy and implement the same procedures. We firmly believe that manuscripts submitted to our journals are the intellectual property of the authors, not the study sponsor. Academic freedom includes the right of authors to have access to all of the data obtained in their study, to review it, obtain statistical analyses independently, and to publish their data based on their own decisions and not those of the financial sponsor. ${ }^{1-3}$ We will now require the principle author to declare in writing that he or she will take full responsibility for the data, the analyses and interpretation, and the conduct of the research: that he or she had full access to all of the data: and that he or she had the right to publish any and all data, separate and apart from the attitudes of the sponsor. Without these written assurances, we will not consider the paper for review. We believe that this new policy will ensure not only greater academic freedom, but also increased credibility for data in our journals that have been the product of academic and corporate alliances.

\section{ACKNOWLEDGEMENT}

"Copyright 2001 American Medical Association". With this inclusion full permission to publish is granted.

J Neurol Neurosurg Psychiatry 2002;72:143

\section{Authors' affiliations}

Roger N Rosenberg, Editor, Archives of Neurology

Michael Aminoff, Editor, Muscle and Nerve Francois Boller and Per Soelberg Soerensen, Co-editors-in-chief, European Journal of Neurology

Robert C Griggs, Editor in Chief, Neurology Vladimer Hachinski, Editor, Stroke

Mark Hallett, Editor, Clinical Neurophysiology Richard T Johnson, Editor, Annals of Neurology

Christopher Kennard, Editor, Journal of Neurology, Neurosurgery, and Psychiatry Anthony E Lang and Andrew J Lees, Co-Editors in Chief, Movement Disorders Robert Lisak, Editor, Journal of the Neurological Sciences

John Newsom-Davis, Editor, Brain

T A Pedley, Editor-in-Chief, Epilepsia

Michael E Selzer, Editor, Neurorehabilitation and Neural Repair

Douglas Zochodne, Editor-in-Chief, Canadian Journal of Neurological Sciences

\section{REFERENCES}

1 DeAngelis CD, Fontanarosa PB, Flanagin A. Reporting financial conflicts of interest and relationships between investigators and research sponsors. JAMA 2001;286:89-91.

2 Davidoff F, DeAngelis CD, Drazen JM, et al. Sponsorship, authorship and accountability. N Engl J Med 2001:345:825-7.

3 Davidson F, Smith R, Squires BP, et al. (International Committee of Medical Journal Editors). Uniform requirements for manuscripts submitted to biomedical journals. JAMA 1997; 277:927-34. 